\title{
Hepatoprotective activity of alcoholic and aqueous extracts of leaves of Tylophora indica (Linn.) in rats
}

\author{
Vipul Gujrati, Nilesh Patel, Venkat N. Rao, K. Nandakumar, T.S. Gouda, Md. Shalam, \\ S.M. Shanta Kumar*
}

Departments of Pharmacology and *Pharmaceutical Chemistry, V. L. College of Pharmacy, Raichur, India

Received: 1.3 .2006

Revised: 20.6.2006

Accepted: 21.7.2006

Correspondence to: N. Venkat Rao E-mail: vrngadda@rediffmail.com

\section{Introduction}

The liver is the key organ regulating homeostasis in the body. It is involved with almost all the biochemical pathways related to growth, fight against disease, nutrient supply, energy provision and reproduction. ${ }^{[1]}$ The liver is expected not only to perform physiological functions but also to protect against the hazards of harmful drugs and chemicals.

In spite of tremendous scientific advancement in the field of hepatology in recent years, liver problems are on the rise. Jaundice and hepatitis are two major hepatic disorders that account for a high death rate. ${ }^{[2,3]}$ Presently only a few hepatoprotective drugs and that too from natural sources (there is not a single effective allopathic medication), are available for the treatment of liver disorders.

Tylophara indica is a branching climber or shrub that grows up to 1.5 meter found in the eastern and the southern regions of India. The leaves are ovate-oblong to elliptic-oblong, 3-
$10 \mathrm{~cm}$ long and $1.5-7 \mathrm{~cm}$ wide. ${ }^{[4]}$ The plant has been traditionally used for the treatment of bronchial asthma, jaundice and inflammation. ${ }^{[4,5]}$ Its antitumor, ${ }^{[6]}$ immunomodulatory, ${ }^{[7-9]}$ antioxidant, ${ }^{[10]}$ anti-asthmatic, ${ }^{[11]}$ smooth muscle relaxant, antihistaminic, hypotensive, antiinflammatory, analgesic, anticonvulsant, and antirheumatic $^{[12]}$ activities are scientifically proven. Although the leaf and root of this plant are widely used for treating jaundice in Northeastern Karnataka, ${ }^{[4]}$ there is a paucity of scientific evidence regarding its usage in liver disorders. Hence, the present study was aimed to investigate the hepatoprotective activity of leaf extracts of T. indica in ethanolinduced hepatotoxic model in rats.

\section{Materials and Methods}

Drugs and chemicals

Silymarin was obtained from Micro Labs, Bangalore. The 
kits for all biochemical estimations were purchased from Transasia Biomedicals Ltd., Daman, India. The solvents and other chemicals used were of analytical grade.

\section{Plant material and extracts}

The leaves of $T$. indica were collected during June-July of 2005 from the fields of Raichur, Karnataka; were authenticated by a botanist, Professor Srivatsa of LVD College, Raichur and a voucher specimen (C-2516) deposited. The leaves were shade-dried at room temperature and the alcoholic extract (ALLT) was obtained with 95\% v/v alcohol for 18 hour, using soxhlet apparatus. The aqueous extract (AQLT) was prepared with the remaining mass by a maceration process for 7 days. The extracts were dried at $50^{\circ} \mathrm{C}$ in a water bath. The percentage yield of ALLT and AQLT were $11.16 \%$ and $18.22 \%$, respectively.

\section{Phytochemical screening}

A preliminary phytochemical screening of ALLT and AQLT was carried out as described by Khandewal. ${ }^{[13]}$

\section{Animals}

Swiss albino mice (18-20 gram) and Wistar albino rats (100-150 gram) of either sex were procured from Sri Venkateshwara Enterprises, Bangalore and were acclimatized for 10 days under standard housing conditions maintained at a room temperature of $24 \pm 1^{\circ} \mathrm{C}$; relative humidity $45-55 \%$ with 12:12 hour light/dark cycle. The animals had free access to rat food (Lipton Gold Mohr, India) and water. The animals were habituated to laboratory conditions for 48 hour prior to the experimental protocol to minimize any nonspecific stress. The Institutional Animal Ethics Committee of V.L College of Pharmacy, Raichur, India, approved the experimental protocol in accordance with the guidelines provided by Committee for the Purpose of Control and Supervision of Experiments on Animals (CPCSEA) with registration number 557/02/C/ CPCSEA.

\section{$L D_{50}$ determination}

Acute oral toxicity (AOT) of ALLT and AQLTwere determined using nulliparous, non-pregnant female mice. The animals were fasted for 3 hour prior to the experiment and were administered with single dose of extracts dissolved in $2 \% \mathrm{~W} \backslash \mathrm{V}$ Tween 80 and observed for mortality for upto 48 hour (shortterm toxicity). Based on the short-term toxicity, the dose of the next animal was determined as per OECD guideline 425. ${ }^{[14]}$ All the animals were also observed for long-term toxicity (14 days). The $\mathrm{LD}_{50}$ of the test extracts were calculated using 'AOT 425' software provided by Environmental Protection Agency, USA.

\section{Hepatoprotective activity}

Hepatoprotective study was carried out as described by Shukla et al. ${ }^{[15]}$ Albino rats of either sex (150-200 gram) were selected and divided into seven groups of six animals each. The animals were pretreated twice daily with vehicle $(2 \% \mathrm{v} / \mathrm{v}$ tween 80)/ALLT (200 and $500 \mathrm{mg} / \mathrm{kg}$ )/AQLT (125 and $300 \mathrm{mg} /$ $\mathrm{kg}) /$ silymarin $(100 \mathrm{mg} / \mathrm{kg})$ orally, 1 hour before ethanol administration. All the animals, except normal control group, received ethanol $(3.76 \mathrm{~g} / \mathrm{kg}$, p.o) twice daily for a period of 25 days. On day 26, thiopentone sodium ( $40 \mathrm{mg} / \mathrm{kg}$, i.p) was injected and the sleeping time recorded in all the animals.

The same animals were then anesthetized using anesthetic ether, 1 hour after complete recovery from thiopentone sodium effect and blood collected by retro orbital puncture. The levels of serum alanine transaminase (ALT), aspartate transaminase (AST), alkaline phosphatase (ALP), direct and total bilirubin, cholesterol, triglycerides, total proteins and albumin were estimated as per the standard procedures prescribed by the manufacturer (Transasia Biomedicals Ltd., Daman, India). Immediately after the collection of, blood the animals were euthanized with an overdosage of ether; their livers removed, washed in saline and the wet weight and volume determined. Histopathology of liver was carried out by a modified method of Luna. ${ }^{16 \mid}$ In brief, the autopsied livers were washed in normal saline and fixed in $10 \%$ formalin for 2 days followed with bovine solution for 6 hour. Then the livers were paraffin embedded and $5 \mu$ thickness microtome sections made. The sections were processed in alcohol-xylene series and stained with haematoxylin and eosin. The slides were studied under a light microscope for any histological damage/protection.

Statistical analysis

The data are expressed as mean \pm SEM. Statistical differences between means were determined by one-way Anova followed by Tukey Kramer's post hoc test. Values of $P<0.05$ were considered as significant.

\section{Results}

Preliminary phytochemical studies revealed the presence of alkaloids, carbohydrates, steroids, saponins, and triterpenes in ALLT while alkaloids, carbohydrates, and saponins were noticed in AQLT. The ALLT was found to be nontoxic up to a dose of $5000 \mathrm{mg} / \mathrm{kg}$ and the $\mathrm{LD}_{50}$ of AQLT was found to be $3162 \mathrm{mg} / \mathrm{kg}$.

Treatment of rats with ethanol produced an increase in the weight and volume of wet liver. Rats pretreated with silymarin, ALLT and AQLT showed significant decrease in wetliver weight and volume compared to control (toxic) group [Figure 1].

Ethanol administration resulted in significant elevation of AST, ALT, SALP, triglycerides, cholesterol, direct bilirubin and total bilirubin levels, while total protein and albumin were found to be decreased compared to normal control group. Pretreatment with silymarin, ALLT or AQLT significantly prevented the biochemical changes induced by ethanol. The hepatoprotective effect offered by ALLT was found to be significantly greater than AQLT treatment [Table 1].

A significant reduction in thiopentone-induced sleep time was observed with both the extracts as compared to the ethanol-treated control group [Table 2]. The ALLT treatment greatly reduced the thiopentone sleep time as compared to AQLT [Figure 2].

Hepatocytes of the normal control group showed a normal lobular architecture of the liver. In the ethanol-treated group the liver showed microvascular fatty changes and the hepatocytes were surrounded by large number of fat droplets. Silymarin-, ALLT- and AQLT-pretreated groups showed minimal fatty changes [Figure 3] and their lobular architecture was normal, indicating the hepatoprotective effect of these extracts. However, AQLT showed more microvascular fatty changes 
Figure 1: Effect of ALLT and AQLT on liver weight and volume in ethanol induced hepatotoxic rats

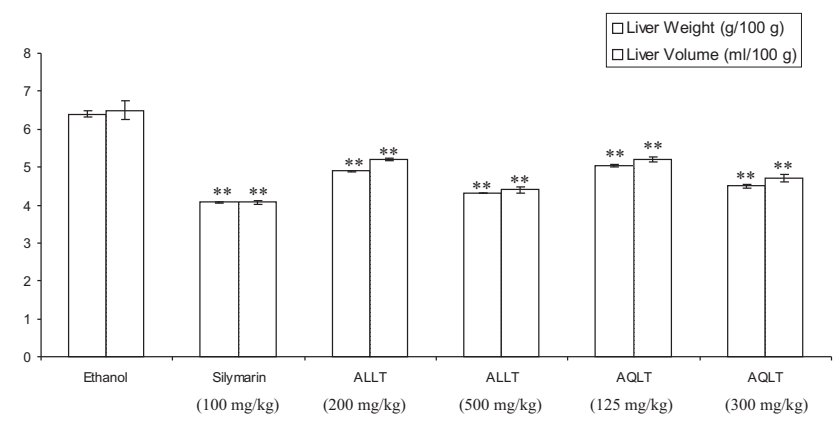

Results are expressed as Mean \pm SEM obtained from 6 animals. ${ }^{* *} P<0.01$ vs ethanol treated group.

Figure 2: Effect of ALLT and AQLT on thiopentone induced sleeping time in ethanol induced hepatotoxic rats

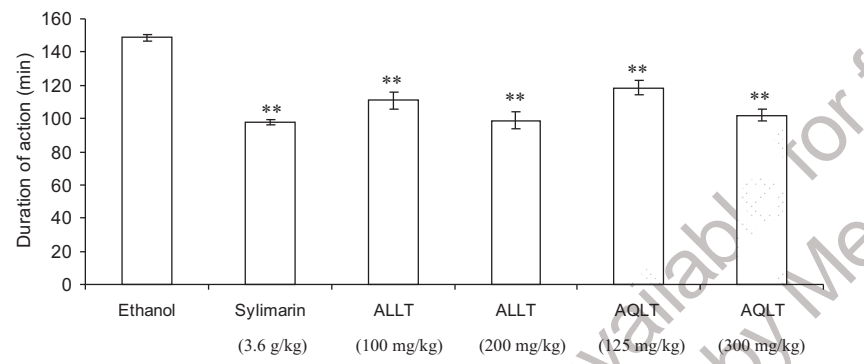

Results are expressed as Mean \pm SEM obtained from 6 animals. ${ }^{* \star} P<0.01$ vs ethanol treated group.

[Figure 3E] than ALLT. The hepatoprotective activity of the extracts were in the order of Silymarin > ALLT > AQLT.

\section{Discussion}

The liver can be injured by many chemicals and drugs. In the present study ethanol was selected as a hepatotoxicant to induce liver damage, since it is clinically relevant. Ethanol produces a constellation of dose-related deleterious effects in the liver. ${ }^{[17]}$ In chronic alcoholics, hepatomegaly occurs due to accumulation of lipids and proteins in hepatocytes ${ }^{|18|}$ with an impaired protein secretion by hepatocytes. ${ }^{[19]}$ Water is retained in the cytoplasm of hepatocytes leading to enlargement of liver cells, resulting in increased total liver mass and volume ${ }^{201}$ as observed in the present study. This alcohol-induced increase in total wet-liver weight and volume was prevented by pretreatment with Tylophora indica leaf extracts, thus indicating a hepatoprotective effect.

During hepatic damage, cellular enzymes like AST, ALT and ALP present in the liver cells leak into the serum, resulting in increased concentrations. ${ }^{211}$ Ethanol administration for m

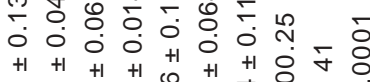

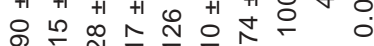

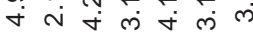

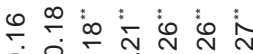

के के

$0.0 \%$

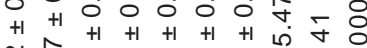

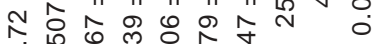

0 लें

\&

$\frac{10}{2}$

$-\infty<\infty$ 我

$+1+1+1+1+1+1$

ल

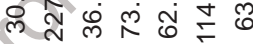

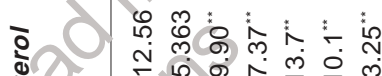

क. $+1+1+1+1+1+1+\infty$

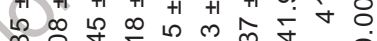

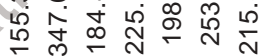

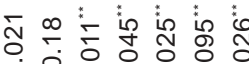

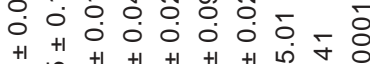

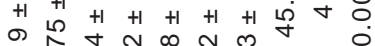

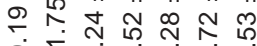

0 - 0 O 0 O 0

กั

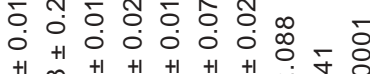

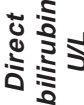

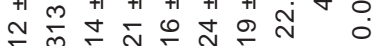

б.:

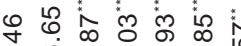

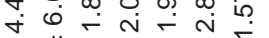

$++1-N-N-m$

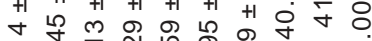

遂

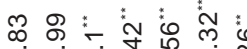

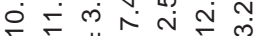

$-1+1+1+1+1+1+1=\overline{0}$

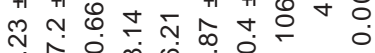

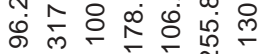

م

- L

$+1+1-1+1+4$ i

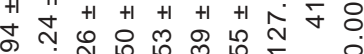

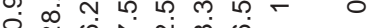

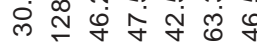

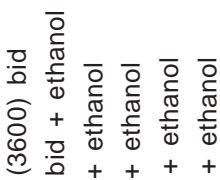

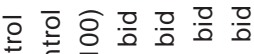

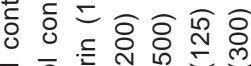

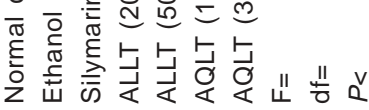


Figure 3: Histology of liver showing normal hepatocytes (a), ethanol induced microvascular fatty changes surrounded by large number of small fatty droplets (b), hepatocytes in groups treated with silymarin (c), ALLT (500 mg/kg) (d) and AQLT (300 mg/kg) (e) prior to administration of ethanol showing minimal fatty changes

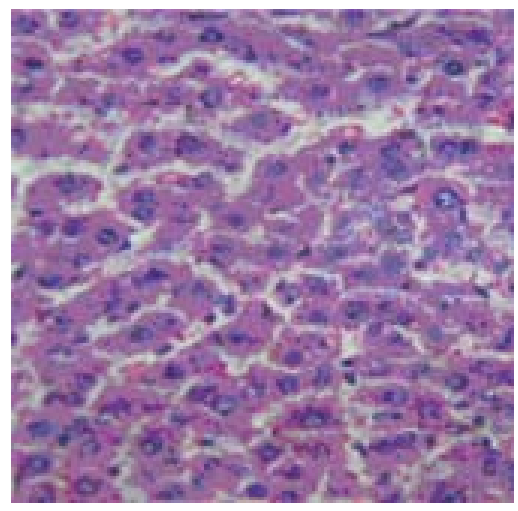

$\mathbf{a}$

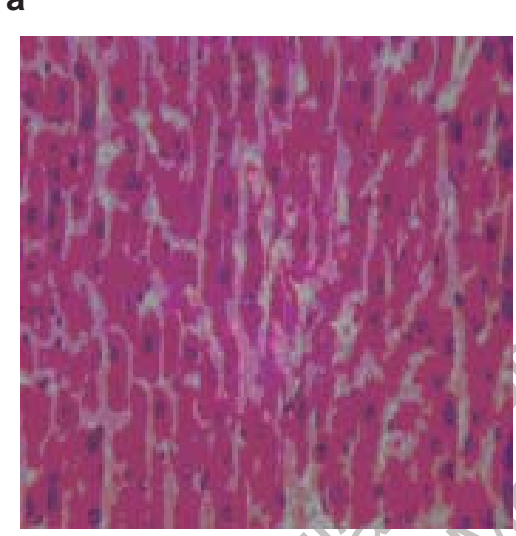

d

25 days significantly increased all these serum enzymes, whereas the Tylophora indica leaf extract- (ALLT or AQLT) pretreated animals had significantly reduced AST, ALT, and SALP levels and increased total protein and serum albumin levels, indicating their hepatoprotective effect against alcohol -induced liver cell damage.

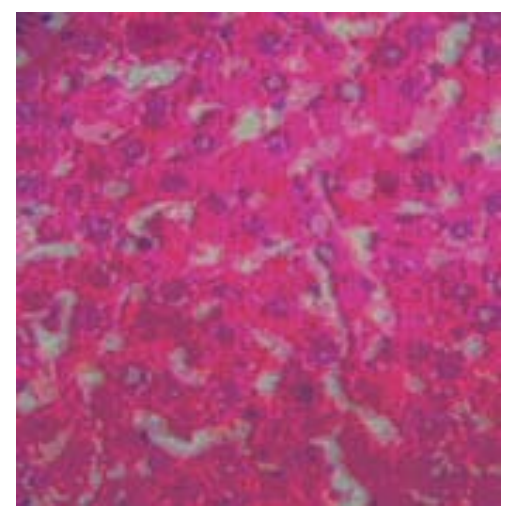

b
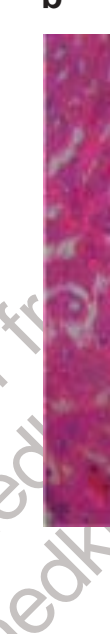

Ethanol induces hypercholesteremia and hypertriglyceridemia, which may be due to the activation of enzyme HMG CoA reductase, the rate-limiting step in cholesterol biosynthesis. ${ }^{22]}$ The increased serum triglyceride level in ethanol-treated rats may be due to the decreased activity of lipoprotein lipase, which is involved in the uptake

Table 2

Effect of ALLT and AQLT on liver weight and liver volume and thiopentone-induced sleeping time in ethanol-induced hepatotoxic rats

\begin{tabular}{|c|c|c|c|c|}
\hline \multirow[t]{2}{*}{ Treatment p.o. } & \multirow{2}{*}{$\begin{array}{c}\text { Mean liver weight } \\
(g / 100 g)\end{array}$} & \multirow{2}{*}{$\begin{array}{c}\text { Mean liver volume } \\
\text { (mL/100g) }\end{array}$} & \multicolumn{2}{|c|}{ Thiopentone induced sleeping } \\
\hline & & & Onset(s) & Duration (min) \\
\hline Normal control $(2 \% \mathrm{v} / \mathrm{v}$ tween $80,1 \mathrm{~mL} / \mathrm{kg})$ & $3.77 \pm 0.070$ & $3.05 \pm 0.26$ & $173.5 \pm 4.0$ & $87.5 \pm 1.18$ \\
\hline Ethanol control p.o. $(3.76 \mathrm{~g} / \mathrm{kg})$ & $6.43 \pm 0.022$ & $6.53 \pm 0.043$ & $83.67 \pm 4.60$ & $148.83 \pm 2.02$ \\
\hline Silymarin $(100 \mathrm{mg} / \mathrm{kg})+$ ethanol & $4.075 \pm 0.021^{* *}$ & $4.07 \pm 0.048^{* *}$ & $159.17 \pm 4.30^{* *}$ & $97.83 \pm 1.35^{* *}$ \\
\hline Alcoholic extract $(200 \mathrm{mg} / \mathrm{kg})+$ ethanol & $488 \pm 0.048^{* *}$ & $5.22 \pm 0.086^{* *}$ & $144.83 \pm 2.51^{* *}$ & $111.16 \pm 5.13^{* *}$ \\
\hline Alcoholic extract $(500 \mathrm{mg} / \mathrm{kg})+$ ethanol & $4.336 \pm 0.035^{\star *}$ & $4.452 \pm 0.074^{* *}$ & $154.33 \pm 4.18^{* *}$ & $98.66 \pm 5.08^{* *}$ \\
\hline Aqueous extract $(125 \mathrm{mg} / \mathrm{kg})+$ ethanol & $5.05 \pm 0.052^{* *}$ & $5.27 \pm 0.10^{\star *}$ & $127.5 \pm 4.23^{* *}$ & $118.67 \pm 4.36^{* *}$ \\
\hline Aqueous extract $(300 \mathrm{mg} / \mathrm{kg})+$ ethanol & $4.55 \pm 0.040^{* *}$ & $4.74 \pm 0.094^{\star *}$ & $142.33 \pm 4.96^{* *}$ & $102 \pm 3.62^{\star *}$ \\
\hline $\mathrm{F}=$ & 388.33 & 79.105 & 48.323 & 30.898 \\
\hline$d f=$ & 41 & 41 & 41 & 41 \\
\hline$P<$ & 0.0001 & 0.0001 & 0.0001 & 0.0001 \\
\hline
\end{tabular}

Results are expressed as mean \pm SEM, $n=6,{ }^{* *} P<0.01$ vs ethanol-treated group using one-way ANovA followed by Tukey Kramer's post hoc test 
of triglyceride-rich lipoprotein by the extrahepatic tissues. ${ }^{[2]}$ Pretreatment with ALLT or AQLT reduced the elevated cholesterol and triglyceride levels, suggesting that the extracts prevented ethanol-induced hyperlipidemia probably due to their hepatoprotective activity.

Ethanol also alters the metabolic activity of hepatocytes, thereby inducing hepatic damage. Barbiturates are a class of xenobiotics that are extensively metabolized in the liver. Deranged liver function leads to delay in the clearance of barbiturates, resulting in a longer duration of hypnotic effect. ${ }^{|23|}$ In the present study, administration of thiopentone sodium to rats pretreated chronically with alcohol resulted in an increased duration of thiopentone sleep time. Pre-treatment with Tylophora indica leaf extracts decreased thiopentone-induced sleep time, an indirect evidence of their hepatoprotective effect.

Histological changes such as steatosis (fatty changes in hepatocytes) and perivenular fibrosis were observed in ethanoltreated (toxic) control group. Both the extracts prevented these histological changes, further indicating their hepatoprotective activity. All the histological changes observed were in correlation with the physical, biochemical, and functional parameters of the liver.

Ethanol, even after short-term consumption, induces CYP2E1 enzyme activity in doses that do not cause fatty changes. This enzyme accelerates alcohol metabolism with a resultant increase in acetaldehyde production. ${ }^{[24]}$ Acetaldehyde is thought to have a number of adverse effects like decreased transport and secretion of proteins owing to tubulin polymerization, enhanced vitamin metabolism and trace metals and drugs like paracetamol cause severe acute liver injury which is sometimes fatal. ${ }^{[25-27]}$ Antioxidants exhibit hepatoprotective activity by blocking the conversion of ethanol to acetaldehyde. ${ }^{|28|}$ From the previous studies it was found that Tylophora indica has exhibited an antioxidant property ${ }^{101}$ which may be responsible for the hepatoprotective activity of these two extracts. The presence of secondary metabolites like alkaloids, steroids, saponins, and triterpenes in these extracts may be responsible for the hepatoprotective activity. Moreover, better hepatoprotective activity observed with ALLT may be due to the presence of steroids. Further work is in progress to isolate and characterize the active principles in the extracts.

It can be concluded that Tylophora indica leaf extracts possess a protective effect against ethanol-induced hepatotoxicity in rats, as evidenced by the physical, biochemical, functional and histological parameters.

\section{Acknowledgment}

Authors are thankful to all the management members of AME's VL College of Pharmacy, for providing the necessary facilities to conduct this study and are thankful to Dr. S. M. Mahantappa, Navodaya Medical College and Research Centre, Raichur, for his help pertaining to histopathological study.

\section{References}

1. Ward FM, Daly MJ. Hepatic disease. In: Walker R, Edwards C, editors. Clinical Pharmacy and Therapeutics. Churchill Livingstone: New York;
1999. p. $195-212$

2. Pang S, Xin X, Stpierre MV. Determinants of Metabolic Disposition. Ann Rev Pharmacol Toxicol 1992;32:625-6.

3. Ross MH, Romrell LJ, Kaye GI. Histology a text and atlas. Wiliam and Wilkins: Baltimore; 1996.

4. Kirtikar KR, Basu BD. Indian Medicinal Plants. $2^{\text {nd }}$ ed. Periodic Experts Book Agency: New Delhi; 1991

5. Chopra IC, Chopra RN, Nayar SL. Glossary of Indian Medicinal Plants. Council of Scientific and Industrial Research: New Delhi; 1986.

6. Huang X, Gao S, Fan L, Yu S, Liang X. Cytotoxic alkaloids from the roots of Tylophora atrofolliculata. Planta Med 2004;70:441-5.

7. Ganguly T, Badheka LP, Sainis KB. Immunomodulatory effect of Tylophora indica on Con A induced lymphoproliferation. Phytomedicine 2001;8: 431-7.

8. Ganguly T, Sainis KB. Inhibition of cellular immune responses by Tylophora indica in experimental models. Phytomedicine 2001;8:348-55.

9. Gopalakrishnan C, Shankaranarayanan D, Nazimudeen SK, Kameswaran L. Effect of tylophorine: A major alkaloid of Tylophora indica, on immunopathological and inflammatory reactions. Indian J Med Res 1980;71:940-8.

10. Jagetia GC, Baliga MS. The evaluation of nitric oxide scavenging activity of certain Indian medicinal plants in vitro: A preliminary study. J Med Food 2004; 7:343-8

11. Huntley A, Ernst E. Herbal medicines for asthma: A systematic review. Thorax 2000;55:925-9.

12. Gopalakrishnan C, Shankaranarayan D, Kameswaran L, Natarajan S. Pharmacological investigations of tylophorine, the major alkaloid of Tylophora indica. Indian J Med Res. 1979;69:513-20.

13. Khandelwal KR. Practical Pharmacognosy Techniques and Experiments. $9^{\text {th }}$ ed. Nirali Prakashan: Pune; 2000.

14. OECD 2001-gudeline on acute oral toxicity (AOT). Environmental health and safety monograph series on testing and adjustment. No. 425.

15. Shukla V, Tiwari RK, Agarwal DP. Hepatoprotective role of Picroliv isolated from Picrohiza kurroa on alcohol induced liver necrosis. Adv Pharmacol Toxicol 2001;2:9-16.

16. Luna LG. Manual in histology and staining methods. McGraw Hill: New York; 1999.

17. Leo MA, Arai M. Hepatotoxicity of vitamin A and ethanol in rat. Gastroenterology 1982;82:194-205.

18. Ashakumary L, Vijayammal PL. Additive effect of alcohol and nicotine on lipid metabolism in rats. Indian J Exp Biol 1993;31:270-4.

19. Vilstrup H, Tygstrup N. Glucoregulation in acute liver failure. Eur J Clin Invest 1985;16:193-7.

20. Blancho CD, Gentil S. Alterations of glucose metabolism in chronic liver disease. Diab Res Clin Prac 1990;8:29-36.

21. Deb AC. Fundamentals of biochemistry. $7^{\text {th }}$ ed. New Central Book Agency: Kolkata; 1998.

22. Younes $M$, Strubelt $O$. Alcohol induced hepatotoxicity: A role for oxygen free radicals. Free Radic Res Common 1987;3:19-26.

23. Kulkarni SK. Hand book of experimental pharmacology. $3^{\text {rd }}$ ed. Vallabh Prakashan: New Delhi; 1999.

24. Lieder CS, DeCarli LM. Hepatic Microsomal ethanol oxidzing system: In vitro characterisitcs and adapative properties in vivo. J Biochem 1970;245:2505-12.

25. Fromenty B, Pessayre D. Impaired mitochondrial function in microvesicular steatosis. Effect of drugs, ethanol, hormones and cytokines. J Hepatol 1997;26:43-53.

26. McClain CJ, Kromhount JP. Potentiation of acetaminophen hepatotoxicity by alcohol. JAMA 1980;244:251-3.

27. Seeff LB, Adler E. Acetaminophen hepatotoxicity in alcoholics. A therapeutic misadventure. Ann Int Med 1986;104:399-404.

28. Maneesh M, Jayalakshmi H. Effect of ascorbic acid, alpha tocopherol, lecithin and L-ornithine-L-asparate on ethanol induced hypoproteinemia and hyperlipidaemia in rats. Indian J Physiol Pharmacol 2005;49:422-6. 